Disponível em www.scielo.br/paideia

\title{
Inserção social universitária: Uma investigação com base no átomo social mínimo
}

\author{
Juliana Cal Auad \\ Maria Inês Gandolfo Conceição \\ Universidade de Brasília, Brasília-DF, Brasil
}

\begin{abstract}
Resumo: Ao longo da história, os deficientes ocupam um lugar de marginalização e sua inserção depende, em grande parte, do contexto social. Este trabalho se propôs a mapear as redes sociais de alunos universitários com deficiência física a partir de uma leitura psicodramática e identificar como o aluno avalia sua inserção a partir dos papéis desempenhados. Criou-se um instrumento inspirado no átomo social de Moreno e no Mapa Mínimo proposto por Sluzki, que se denominou átomo mínimo. Participaram da pesquisa sete estudantes universitários com deficiência física que foram entrevistados com base no instrumento criado. Os resultados indicam que os participantes desempenham diferentes papéis na família e no ambiente de trabalho/estudo, a universidade foi apontada como um local em que puderam testar seus limites e desenvolver laços de amizade. A maior dificuldade de inserção aponta o problema de locomoção dentro do campus. Percebe-se a necessidade de maiores subsídios para políticas de inclusão universitária.
\end{abstract}

Palavras-chave: Inclusão social. Psicodrama. Deficiente físico.

\section{College social insertion: An investigation based on the minimum social atom}

\begin{abstract}
It is evident through history that disabled individuals occupy marginal positions and their insertion depend, in great part, on the social context. This study aims to investigate the social networks of college students with disabilities from a psychodramatic point of view. To achieve such goal, a new instrument called minimal atom, was created. This instrument was based on Moreno's social atom theory and Sluzki's minimal map. The interview and instrument were applied to seven students with physical disabilities. Results indicate that people with disabilities develop different roles in their families and at work/college. The university seems to be a place where these students can test their limits and develop friendships. The major difficulty for their inclusion in the university is related to their ability of moving around the campus. There is a clear need of supporting public policies for college inclusion criteria.
\end{abstract}

Keywords: Social inclusion. Psychodrama. Physically disabled.

\section{Inclusión social universitaria: Una investigación con base en el átomo social mínimo}

Resumen: Al largo de la historia, los discapacitados ocupan un lugar de marginalización y su integración depende, en gran parte, del contexto social. Este trabajo se propone a dibujar el mapa de las redes sociales de alumnos universitarios con discapacidad física desde una lectura psicodramática e identificar como este alumno evalúa su integración desde los papeles desarrollados. Se creó un instrumento inspirado en el átomo social de Moreno y en el Mapa Mínimo propuesto por Sluzki, que se denominó átomo mínimo. La investigación se realizó con siete participantes con discapacidad física que fueron entrevistados por medio del nuevo instrumento. Los resultados indican que los participantes, juegan diferentes papeles en la familia y en el ambiente de trabajo/estudio. La universidad fue señalada como el sitio donde estos alumnos pudieran probar sus límites y desarrollar lazos de amistad. La mayor dificultad de integración está en el problema de la locomoción dentro del campus. Se percibe una necesidad de más recursos para políticas de integración universitaria.

Palabras clave: Inclusión social. Psicodrama. Deficiente físico. 
A deficiência é um tema que está ganhando cada vez mais espaço na mídia e nas regras normativas dos países. Ela evidencia que cada um de nós é singular. Uma sociedade minimamente igualitária pressupõe equiidade entre todos os cidadãos, seja de acesso ao mercado de trabalho, à informação, assim como possibilidades de deslocamento na cidade (Correr, 2003). Diaz (1995) destaca que o tratamento dado aos deficientes varia ao longo da história a partir da época e da cultura, mas há uma constante histórica que permanece: a marginalização. A inserção desses depende muito mais do contexto social do que das capacidades dos deficientes.

Nos dias de hoje, a deficiência é vista como um fenômeno relativo e relacional (Organização Mundial da Saúde [OMS], 1997). Isso significa que ter uma limitação física não implica ter uma deficiência, uma vez que o ambiente no qual o indivíduo está inserido pode não ser limitador de sua participação nas atividades diárias. Nessa perspectiva, Verbrugge e Jette (1994) destacam que a maneira como a pessoa lida com a deficiência depende de fatores sociais, psicológicos e funcionais. As relações estabelecidas entre as pessoas com necessidade especial e membros da sociedade em que está inserida são determinantes para sua incapacitação. A busca pela inclusão social se dá na perspectiva de garantir o acesso da pessoa com necessidades especiais a todos os espaços da sociedade, independente da tipologia ou gravidade de sua deficiência (Correr, 2003).

A deficiência física é o comprometimento do aparelho locomotor - sistemas osteoarticular, muscular e nervoso. Doenças ou lesões que afetam um ou mais desses sistemas, como lesão medular e malformação congênita, podem levar a quadros de limitação física (Monte \& Santos, 2004). As consequiências de uma deficiência física não se limitam à esfera motora, ela traz inúmeras conseqüências para a pessoa, sua família, amigos e para a sociedade como um todo. Seus efeitos estendem-se sobre praticamente todas as funções vitais do indivíduo e existe um custo emocional incomensurável como conseqüência de uma deficiência (Conceição, 2000).

O enfrentamento pode ser entendido como uma maneira diferente de responder a um problema ou a alguma situação difícil. É a prontidão de um indivíduo em responder de acordo com o que lhe é solicitado. Essa maneira de agir, de dar uma resposta adequada a uma situação nova é chamada, em Psicodrama, de espontaneidade (Fox, 2002; Moreno, 1975). A espontaneidade deve ser compreendida a partir de quatro critérios: impulso; aquisição cultural, ou criatividade; criação de livre expressão, originalidade; adequação da resposta, in situ (Moreno, 1975). A espontaneidade é percebida quando o deficiente é capaz de emitir uma resposta que seja nova, criativa e adequada ao seu contexto cultural, sua existência deve-se à conserva cultural. Nenhuma das duas existe em sua forma pura, sendo uma parasita da outra (Moreno, 1975). A conserva cultural tem a função de preservação e continuidade do ego, assim permite a manutenção de uma herança cultural. Por mais que as conservas sejam tranqüilizadoras, são também a maior barreira à infiltração da espontaneidade e à criatividade do homem, por diminuir a necessidade de ações espontâneas ou de inspirações momentâneas (Moreno, 1975; Fox, 2002).

Espontaneidade é a capacidade de adaptação do homem de se adequar ao novo, diz respeito à mobilidade e flexibilidade do "eu", característica vital e essencial à sua existência. É criada a cada instante, para cada circunstância (Moreno, 1975, 1999). A liberação dessa espontaneidade permite que as pessoas evoluam psiquicamente, uma vez que as alforria do "determinismo absoluto" (Nery, 2003, p. 20). Nas palavras de Naffah Neto (1989, p. 105), "Espontaneidade é a plasticidade, mobilidade da conduta, num papel flexível, ou seja, quando diferentes marcas da superfície do corpo catalisam múltiplos fluxos, sem dominação exclusiva de nenhum deles". $\mathrm{O}$ autor questiona a espontaneidade como relação de adequação, uma vez que entende que a espontaneidade deve ser vista como a capacidade de reconquistar a relação de interioridade e de sentido que caracteriza a relação sujeito-mundo, cada vez que ela é rompida por uma mudança inesperada: "a conduta é antes um esforço de abertura e de recuperação do real do que uma adequação (...) a relação é sobretudo de compromisso, não de ajustamento" (Naffah Neto, 1979, p.40).

A interação social é outro aspecto amplamente estudado pela literatura da área, que tem demonstrado 
cada vez mais sua relevância. A atividade social se correlaciona diretamente com a rede social das pessoas. Ou seja, quanto maior a quantidade de atividades que um indivíduo participa, maior será sua rede social. Além disso, os pesquisadores encontraram que quanto maior a rede, menor a incidência de problemas psicológicos (Eide \& Roysamb, 2002). Sherman, Devinney e Sperling (2004) apontam que a interação social é maior quando o lesado medular mora com companheiro(a). Este é um dado esperado, uma vez que um indivíduo que mora com alguém, amplia seu círculo de convívio, pois além de interagir com seus amigos, interage com os amigos do(a) companheiro(a).

O Psicodrama, ao trabalhar as relações interpessoais, se propõe a resolver conflitos de maneira nova e criativa, pois entende o homem como um ser espontâneo (Moreno, 1975). Acredita-se que os problemas psicológicos têm base interacional (Fox, 2002). Portanto, perceber as interações de um indivíduo e analisá-las à luz do psicodrama possibilita mapear a saúde psicológica das pessoas a partir de sua interação com o meio e da percepção que têm dessa interação.

Moreno (1994) tomou o termo átomo derivado do grego significando "qualquer coisa muito pequena", cunhado na física para determinar as menores partículas do universo físico - para descrever as estruturas microscópicas que surgem no contexto das relações humanas - cujos padrões resumem-se à atração, rejeição e indiferença - e que se tornam visíveis nas configurações de indivíduos dentro de um grupo. Assim, o autor define átomo social como a menor unidade funcional dentro do grupo social. Afirma que toda pessoa pode estar relacionada positiva ou negativamente a um número indefinido de pessoas, que, por sua vez, respondem a esta relação positiva ou negativamente. É essa configuração que constitui o átomo social. Na medida em que o indivíduo cresce, vai expandindo seu átomo social, na proporção em que amplia sua rede de relações sociais. Para Naffah Neto (1979), é o átomo social que constitui a menor unidade social e não o indivíduo. $\mathrm{O}$ autor considera o átomo social como um campo de interações intersubjetivas, de interpenetração, oposição e síntese do atual e do virtual, do real e do imaginário, do co-consciente e do coinconsciente. Por sua vez,

o empobrecimento do átomo social é o resultado de qualquer tipo de patologia, constituindo a máxima incapacidade de uma pessoa em conflito: o não-encontro de substitutos para as pessoas básicas de sua matriz (Bustos, 1979, p. 20).

O suporte social é um conceito que está intimamente ligado ao de átomo social que faz referência ao núcleo de relações de um indivíduo (Knobel, 2004). Moreno (1994) o descreve como "a menor unidade social viva, impossível de ser dividida" (p. 159), cujos contornos de sua superfície devem ser descobertos. O átomo permite investigar os vínculos que a pessoa estabelece, o seu núcleo de relações (Moreno, 1975). É a rede social e de apoio de um indivíduo, composta de várias estruturas télicas - fluxo de sentimentos existente nas relações que afastam ou aproximam as pessoas - e de várias redes sociométricas que fazem parte da sociometria de uma sociedade (Moreno, 1994).

Como somos seres em relação, quanto mais relações formos capazes de estabelecer e quantos mais diferentes papéis desempenharmos, mais saudáveis seremos. E se estamos isolados, estamos mais propensos ao sofrimento (Fox, 2002; Moreno, 1994). A filosofia de Moreno afirma que somos todos criadores e co-criadores, vivendo em um mundo de relações interpessoais, interdependentes um do outro (Marineau, 1992). O átomo social, utilizado em seu conceito mais amplo, evidencia os papéis desempenhados pelo indivíduo, além das relações de atraçãorepulsa-neutralidade (Moreno, 1994). O conceito de papel diz respeito às diferentes formas assumidas pelo eu, criada pelas experiências passadas e pelos padrões da cultura em que o indivíduo se insere. Todo papel é tanto a fusão quanto a oposição entre o privado e o coletivo (Fox, 2002), que possibilita o surgimento do eu (Moreno, 1975). Os papéis têm grande importância na comunicação entre as pessoas, pois possibilitam a compreensão interindividual e intercultural e permeiam a cultura em que os indivíduos estão inseridos (Moreno, 1975).

Há três diferentes dimensões dos papéis: papéis psicossomáticos, papéis psicodramáticos e 
papéis sociais. Os papéis psicossomáticos são determinados pelos padrões de interação cuidadorcriança e são anteriores ao surgimento da linguagem. O papel de ingeridor é um desses papéis, que se constitui no processo de alimentação e repercute ao longo da vida de uma pessoa, podendo ser identificado em diferentes momentos da vida. Os papéis psicodramáticos expressam a dimensão psicológica do self e se constituem nos jogos de papel, como a identificação de papéis e o espelho. São os papéis que dizem respeito à representação da psique de um indivíduo quando em um coletivo. Os papéis sociais expressam a dimensão social de um indivíduo, e se constituem a posteriori, baseados nos papéis psicossomáticos e nos psicodramáticos, que são formas prévias de experiência (Fox, 2002; Moreno, 1975). Os papéis sociais apontam os elementos da vida cotidiana que são incorporados à ação das pessoas e dizem respeito à dimensão simbólica da realidade (Knobel, 2004).

Nery (2003) destaca que além dos papéis sociais, a relação das pessoas também é permeada pelos papéis imaginários, latentes e psicodramáticos. Os papéis imaginários constituem-se de desejos e sentimentos não realizados ou criados pela atividade imaginativa. Os papéis latentes são aprendidos no contexto social e não foram ativados devido à falta de complementaridade do vínculo. Por exemplo, um adolescente que nunca tenha namorado, mas o deseja, tem o papel latente de namorado: falta uma namorada para desempenhar o contrapapel, que será articulado ao seu projeto dramático e de seu futuro vínculo.

A importância do átomo social e da discussão do conceito de papel no Psicodrama se assemelha à relevância do conceito de rede social e do modelo de mapa mínimo proposto por Sluzki (1997), na teoria sistêmica. Rede Social é um conceito de suma importância para a teoria sistêmica. Ele diz respeito à noção de sujeito, que inclui suas interações e vínculos interpessoais. A rede social pessoal é composta por todas as relações que a pessoa percebe como significativas, diferenciadas da "massa anônima da sociedade" (Sluzki, 1997, p. 41). É a partir dessa rede que as pessoas constroem seu universo relacional, no qual estabelecem suas relações sociais, e investigando-a, é possível compreender quem faz parte da identidade dos indivíduos.

Sluzki (1997) propõe um modelo de mapa mínimo para a avaliação das redes sociais de uma pessoa e de todos aqueles com os quais ela interage. O mapa se divide em quatro quadrantes, a saber: amizade, família, relações comunitárias e relações do trabalho ou estudo. Esses quadrantes são divididos em três círculos concêntricos, que delimitam a aproximação ou distanciamento das pessoas da rede: relações íntimas, relações pessoais com menor grau de compromisso e relações ocasionais. Tamanho, número de pessoas da rede; densidade, conexão entre os membros da rede independente da pessoa; composição, proporção de membros que está localizada em cada contexto; dispersão, distância entre os membros da rede; homo/heterogeneidade, características sociodemográficas e culturais, são características estruturais importantes no estudo desse mapa. A rede pode exercer diferentes funções: companhia social, apoio emocional, controle social, ajuda material, guia/conselhos e acesso a novos contatos. Os vínculos desse mapa podem ser caracterizados a partir de seus atributos: função predominante, reciprocidade, história da relação, freqüência dos contatos, intensidade e multidimensionalidade. Todas essas variáveis são interdependentes.

É notável a semelhança entre os conceitos de átomo social de Moreno e de mapa mínimo de Sluzki. Ambos fazem referência às pessoas que fazem parte da vida do indivíduo, a quantidade e qualidade das relações estabelecidas, assim como a importância de pessoas que contribuem para a formação da identidade e sentimento de pertença na saúde do indivíduo. Todas essas semelhanças entre os conceitos e suas implicações nas práticas dos profissionais sistêmicos e psicodramatistas, levou à elaboração da proposta deste estudo, que culminou com a criação do que se chamou de "átomo mínimo". Tem-se como objetivo mapear as redes sociais de alunos universitários com deficiência física a partir de uma leitura psicodramática e identificar como o aluno avalia sua inserção a partir dos papéis desempenhados. 


\section{Método}

O estudo assenta suas bases sobre a metodologia de investigação qualitativa que, segundo Demo (2001), busca a essência do fenômeno estudado. González-Rey (2002) corrobora essa idéia ao afirmar que o termo qualitativo se define pelos processos implicados na produção do conhecimento, e não por seus instrumentos ou dados, para este autor, a interação pesquisador-pesquisado é o alicerce da pesquisa qualitativa. Nesta pesquisa, procurou-se não particularizar o estudo do átomo de cada participante, tendo em vista que o objetivo centrou-se no grupamento maior dos universitários com deficiência física, além de ter sido um cuidado adicional para preservar a identidade dos mesmos.

\section{Participantes}

Participaram desta pesquisa sete alunos com deficiência física matriculados em uma universidade e atendidos pelo programa de inclusão social dessa instituição. Os sete participantes, três mulheres e quatro homens, tinham idades entre 23 e 40 anos, com média de 23,87 anos. A renda familiar variou entre R\$ 1.200,00 e 13.000,00, com média de R\$ $5.075,00$. Cinco dos participantes trabalhavam como funcionários públicos e dois não exercem atividade profissional remunerada, dedicando-se exclusivamente aos estudos. Todos os participantes eram solteiros e residiam com as famílias de origem, nenhum deles tinha filhos. Dois participantes moravam em Regiões Administrativas do Distrito Federal-DF e os outros no Plano Piloto.

\section{Instrumentos e procedimentos}

A entrevista clínica foi o instrumento escolhido para essa pesquisa, devido à sua capacidade de adaptação à individualidade de cada participante e devido à prática clínica da pesquisadora, que implica treinamento e habilidade no manejo da técnica. Foi utilizada uma lista de tópicos, criadas a partir das questões norteadoras do estudo e dos objetivos geral e específico. Foram abordados os temas da pesquisa, a saber: (1) Vida atual, relacionamento familiar, vida social, saúde física, rede de suporte, inserção no mercado de trabalho, relato de um dia típico;(2) Vida universitária, relação com colegas, professores e funcionários, programa de inclusão social; (3) História de vida, trajetória escolar até ingresso na uni-versidade, ciclo saúde e doença, uso de medicamentos, avaliação das conquistas e perdas; (4) Expectativa com o futuro, sonhos, perspectiva profissional, como se imagina daqui a cinco, dez, quinze anos.

O átomo social e o mapa mínimo são semelhantes: evidenciam as pessoas que fazem parte da vida do indivíduo, apontam a quantidade e a qualidade das relações estabelecidas, permitem investigar a importância de pessoas na formação da identidade e no sentimento de pertença de um indivíduo. Este estudo propõe um novo instrumento que integra as teorias psicodramática e sistêmica, facilitando a visualização dos vínculos afetivos significativos em seus respectivos contextos.

Embora ambas as abordagens guardem diferentes núcleos epistêmicos, tem-se observado uma crescente produção acadêmica privilegiando a junção entre psicodrama e abordagem sistêmica (dentre eles, Costa \& Vanin, 2005; Seixas, 1992) na complexa tarefa de compreender e tratar as relações humanas. Neste artigo, a proposta de interlocução entre ambas as abordagens contempla prioritariamente o eixo teórico e metodológico da socionomia esboçando uma interface possível com a visão sistêmica novoparadigmática na qual procura-se mobilizar os recursos derivados dos vínculos que constituem as redes sociais, reconhecendo-se a auto-organização e autonomia do sistema (Vasconcellos, 2004). Paralelamente, no método socionômico "há uma ampliação do olhar sobre a sua micro-realidade social para um (olhar) socionômico que considera a complexidade embutida nas intrincadas redes de relacionamentos afetivos" (Nery, Costa \& Conceição, 2006, p. 211). Por sua vez, a concepção sistêmica novo-paradigmática traz implícita uma postura construtivista e construcionista social da realidade, que descreve que a construção do conhecimento psicológico pertence ao domínio do intersubjetivo assim como na teoria socionômica -, no qual os significados são construídos nos espaços comuns de pessoas em relação (Costa \& Vanin, 2005). Por sua 
vez, assume-se em ambas as perspectivas, que somente os envolvidos podem relatar as histórias das tramas relacionais (Grandesso, 2000), ou, em outras palavras: "Somente os protagonistas da história podem descrever como têm sido afetados na sua vida, nos seus relacionamentos, nas visões sobre si mesmos e nas suas perspectivas de futuro" (Costa \& Vanin, 2005, p. 176).

Átomo mínimo é o nome do modelo proposto que integra as teorias psicodramática e sistêmica, a partir de um instrumento que possibilita outras maneiras de compreender e investigar o contexto social no qual os indivíduos de inserem. Neste novo modelo, o procedimento consiste basicamente em pedir ao indivíduo que mostre as pessoas importantes de sua vida no espaço do "como se" - - que pode ser representado de diversas formas: com desenho, em massinha, com recortes de jornal e o que mais a espontaneidade permitir -, e em quatro partes: amizade, família, comunidade, estudo/trabalho. A distância do centro diz respeito à proximidade que a pessoa percebe com relação à outra: relações próximas, relações com menor grau de compromisso e relações ocasionais. A quantidade e a qualidade das relações descritas pelo sujeito, assim como a diversidade de papéis desempenhados, evidenciam a inserção do indivíduo e, portanto, sua saúde psíquica, na medida em que evidenciam a capacidade de se relacionar com o mundo. Por meio do instrumento, o pesquisador pode investigar o átomo social e os papéis desempenhados pelo indivíduo a partir de quatro quadrantes: família, amizade, trabalho/estudo, comunidade. Diferentes aspectos da rede podem ser utilizados na análise deste instrumento: a aproximação ou distanciamento das pessoas da rede, tamanho, densidade, composição e dispersão, homo/heterogeneidade e função da rede.

Neste estudo, os materiais utilizados para a confecção do átomo mínimo foram: folhas de papel e lápis de cor. Dois participantes não quiseram representar graficamente seu átomo mínimo, posição que foi respeitada inclusive em vista das limitações físicas e dificuldade de movimentos motores finos destes. Ambos optaram por relatar quem eram as pessoas importantes de sua vida e falaram dessas relações. Os outros cinco participantes desenharam seu átomo mínimo com lápis de cor. Os desenhos e as falas foram transpostos para o computador, no programa Microsoft Paint - versão 5.1. No átomo mínimo, as pessoas destacadas como importantes foram representadas graficamente: os homens por quadrados e as mulheres por círculos. Buscou-se resguardar o anonimato dos participantes. Para tanto, os átomos mínimos serão apresentados e analisados a partir das semelhanças e diferenças evidenciadas, sem aprofundar em cada participante individualmente.

$\mathrm{O}$ recrutamento dos participantes aconteceu após a aprovação no Comitê de Ética em Pesquisa com Seres Humanos (Registro do Projeto: 036/2006). Antes do início da entrevista foi apresentada a autorização do Comitê de Ética em Pesquisa com Humanos emitida pela Faculdade de Saúde da Universidade de Brasília-UnB a cada participante. Após isso, foi assinado um Termo de Consentimento Livre e Esclarecido que continha o contato da pesquisadora. $\mathrm{O}$ registro de todos os dados foi feito por gravação em gravador de voz digital e por registro escrito. As gravações foram transcritas e analisadas à luz da teoria socionômica.

\section{Resultados e Discussão}

O objetivo desta pesquisa foi mapear as redes sociais de alunos universitários com deficiência física. A partir da observação do átomo mínimo, percebese que os deficientes físicos da universidade em questão desempenham diferentes papéis em suas famílias e no ambiente de trabalho/estudo. A maior parte deles tem relações de amizade, mas não destacam ninguém importante na comunidade. Sua maior dificuldade de inserção na universidade diz respeito ao problema de locomoção dentro do campus universitário, cabendo ressaltar que o já mencionado programa de inclusão social desempenha um papel relevante no cotidiano dessas pessoas. Um dos objetivos específicos do estudo foi identificar como os deficientes físicos percebem sua inserção em

\footnotetext{
${ }^{1} \mathrm{O}$ espaço do "como se" é o "tempo subjetivo" (passado, presente e futuro vividos no aqui e agora), que no setting psicodramático é delimitado pelo palco. Nesta pesquisa, tal espaço - onde tudo é possível - foi circunscrito à folha de papel oferecida para a execução da tarefa.
} 
diferentes esferas: familiar, social, universitária, e no mercado de trabalho. Para tanto, utilizou-se o átomo mínimo.

O átomo mínimo da participante $\mathrm{P} 1$ aponta a importância da família em sua vida, o que é confirmado na entrevista. Solteira, e sem filhos, ela reside com sua família de origem: mãe, irmã e irmão. Não exerce atividade profissional remunerada e dedica-se exclusivamente aos estudos. Seus pais se separam recentemente, o que contribui para a distância do pai, apontada no átomo mínimo, à medida que o convívio diário acabou. P1 estava vivendo um momento de negociação de sua independência junto à família e, especial com relação à mãe. A participante percebe-se como uma pessoa incluída na sociedade.

$\mathrm{O}$ participante $\mathrm{P} 2$ destaca em seu átomo mínimo a importância da relação de amizade que estabeleceu na universidade com um amigo e o desejo de ter uma namorada. Ao longo da entrevista, aponta como a universidade possibilitou que ele conhecesse pessoas que se parecem com ele e que têm gostos semelhantes. A família também foi destacada no átomo mínimo de P2 como uma esfera importante de sua vida, apesar dos conflitos que vivia com a madrasta. O participante é funcionário público e ajuda nas despesas domésticas. Mora distante da universidade e conta com o suporte do pai, que o leva e busca todos os dias às aulas.

$O$ participante P3 não exercia atividade remunerada, mas tinha uma bolsa de estudo. Ele residia com sua irmã, sobrinhos e cunhado e tinha uma relação conflituosa com eles. P3 têm outros irmãos, que residem em outros países e com os quais também têm uma relação conflituosa. Ao longo da entrevista, P3 fala que têm poucos amigos e que sua vida é voltada aos estudos. No átomo social, o participante destaca seu pai e sua mãe, como pessoa com quem pode contar sempre, apesar da distância que os separa.

$\mathrm{O}$ participante $\mathrm{P} 4$ exercia atividade remunerada e ajudava nas despesas domésticas da família. Na esfera da família, P4 destaca seus três irmãos e suas duas irmãs com quem têm um bom relacionamento, além de seus pais. Na esfera da comunidade destaca amigos e vizinhos que moram próximos a ele e com quem também se relaciona bem.
$\mathrm{Na}$ esfera do trabalho, destaca chefes e colegas com quem passa todo o seu dia e com quem tem uma relação amistosa. Seu átomo mínimo é rico, as três das quatro esferas são contempladas e nelas $\mathrm{P} 4$ pode exercer diferentes papéis.

A participante P5 exercia atividade remunerada e morava sozinha na casa que pertencia à sua mãe, falecida recentemente. P5 vivenciava conflitos com os irmãos e tinha poucos amigos, sendo a área de maior número de convivência, o trabalho. Sua referência de família era sua madrinha e primas que residiam em uma cidade distante, mas com quem mantinha contato graças à internet. Apesar de todas as esferas terem sido contempladas no átomo mínimo de P5 e de ela exercer diferentes papéis, sentia-se sozinha e isolada por sair pouco devido às dores que sente.

O participante P6 exercia atividade remunerada e ajudava nas despesas de sua família, com quem residia. A família ocupa um papel central em sua vida, e ele destaca como se reaproximou de sua mãe e pôde conhecer melhor sua irmã, que é mais nova do que ele, após o acidente que causou a lesão medular. P6 destaca ainda a importância do trabalho em sua vida, na medida em que o possibilita a ajudar nas despesas, conhecer novas pessoas e valorizar o conhecimento que tem, a oportunidade de aprender na universidade. É interessante notar que, ao longo da entrevista, P6 fala de muitos amigos, inclusive da faculdade, mas não os destaca no átomo mínimo. Quando questionado sobre isso, relata que é na hora de uma doença que se percebe quem são os verdadeiros amigos, e que neste momento só se pode contar com a família. P6 destaca ainda o desejo de ter uma namorada, mas julga não ter mais os atributos físicos que atraiam uma mulher. Ele considera que está voltando a se incluir na sociedade, mas que o tem feito com muito cuidado, aos poucos.

A participante $\mathrm{P} 7$, assim como o participante P6, também sofreu um acidente que causou uma lesão medular. Também exerce atividade remunerada e ajuda nas despesas da casa de sua família de origem, com quem reside. Considera seu salário importante para não onerar tanto sua mãe com os gastos que teve após o acidente e destaca a reaproximação que teve com a família após o acidente e o questionamento que fez sobre o que é amizade e sua fragilidade. P7 
destaca, em seu átomo mínimo, sua família e um namorado, como pessoas com quem pode contar sempre. Ao longo da entrevista, cita alguns amigos e colegas de trabalho e percebe-se como uma pessoa incluída na sociedade.

Os átomos mínimos dos participantes evidenciam a importância da família como contexto de maior riqueza de interações sociais. É nessa esfera que os participantes têm mais vínculos, na qual desempenham diferentes papéis e contam com apoio e suporte. Lopes, Kato e Corrêa (2002) destacam que o suporte familiar é o aspecto mais benéfico na educação das pessoas com necessidades especiais. Para Tuleski, Taguchi, Alves, Oliveira e Marques (2003), a família é a primeira integradora de uma pessoa com necessidades especiais. Devolver às famílias os seus poderes, sua capacidade e sua responsabilidade na educação de seus filhos é fundamental (Ausloos, 1998). Pelo observado nos átomos mínimos, o suporte da família é também importante no desempenho de diferentes papéis, na sua inserção social e na percepção de existência de uma fonte de apoio e suporte.

Os átomos mínimos dos participantes são compostos de poucas relações e na maior parte deles nem todas as esferas são contempladas (Figuras 1, 2, 3, 4, 6 e 7). A pobreza dos átomos pode estar associada a alguma dificuldade de inserção desses universitários na sociedade. Um número limitado de amigos, colegas de trabalho, a grande importância atribuída à família e a presença de relações conflituosas podem sugerir que os participantes não são incluídos em todas as esferas da sociedade. A rede social diz respeito à inserção do indivíduo na sociedade e também da sociedade na vida das pessoas. Assim, cabe questionar em que medida a sociedade promove a exclusão dessas pessoas, por exemplo, ao perpetuar idéias preconceituosas e ao dificultar o acesso das pessoas com necessidades especiais.

$\mathrm{O}$ átomo mínimo da participante $\mathrm{P} 1$ foi representado por seis elementos distribuídos nos quadrantes da amizade e da família. Os elementos presentes na família são a mãe, a irmã, o irmão e o pai (que se encontra mais afastado) e, na amizade, um amigo e uma amiga.
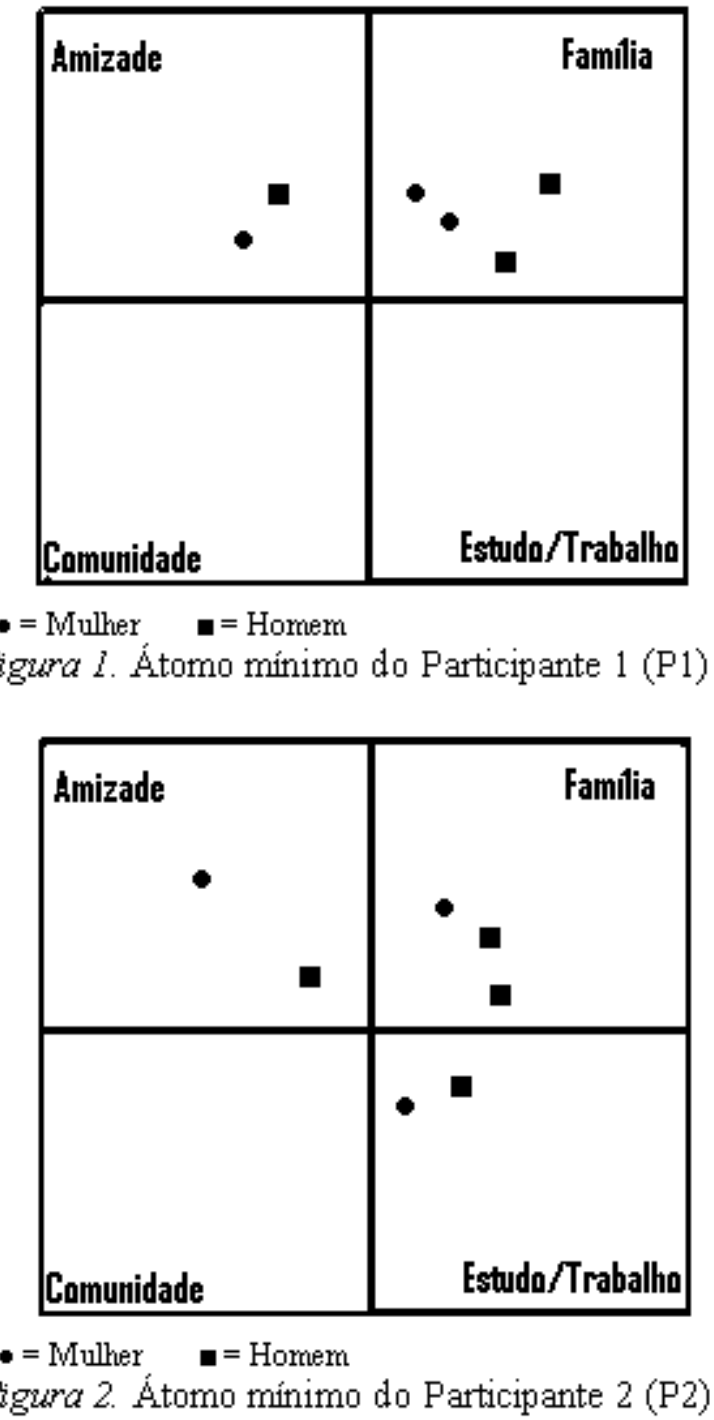

$\mathrm{O}$ átomo mínimo do participante $\mathrm{P} 2$ foi representado por sete elementos distribuídos nos quadrantes de família, estudo/trabalho e amizade. Os elementos presentes na família são pai, irmão e madrasta. Na amizade, destacou um amigo da universidade e o desejo de ter uma namorada. No quadrante trabalho, destacou dois colegas de trabalho.

O átomo mínimo do participante P3 é representado por dois elementos no quadrante família: pai e mãe.

$\mathrm{O}$ átomo mínimo do participante $\mathrm{P} 4$ é composto de oito elementos no quadrante família, 10 no quadrante comunidade, e nove no estudo/trabalho. Na família, destacou o pai e a mãe, os três irmãos, as 


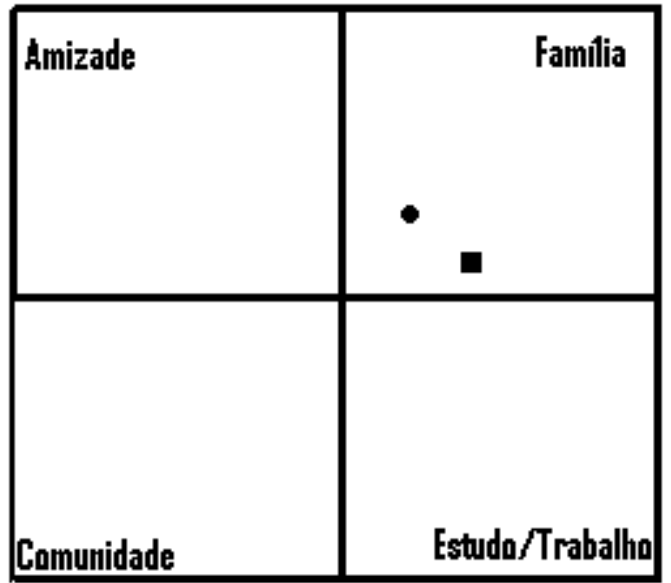

- = Mulher $\quad \boldsymbol{m}=$ Homem

Figura 3. Atomo mínimo do Patticipante 3 (P3)

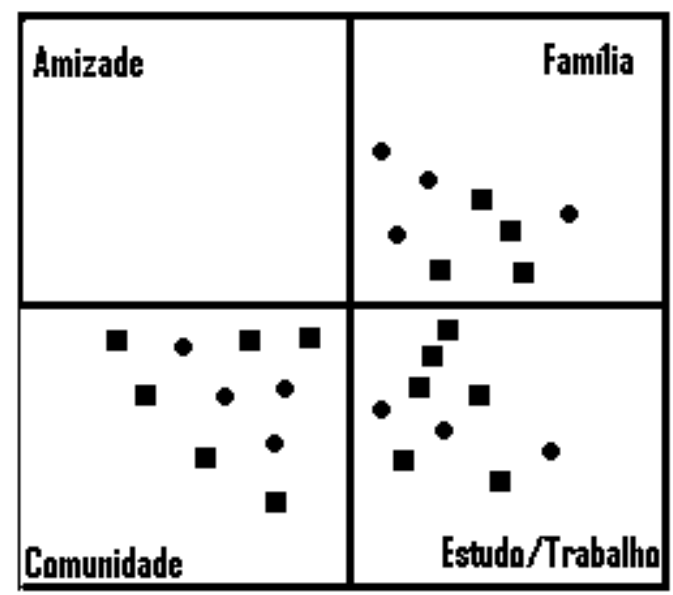

- = Mulher $\quad \boldsymbol{a}=$ Homem

Figura 4. Átomo minimo do Participante 4 (P4)

duas irmãs e uma cunhada. Na comunidade, destacou um vizinho, quatro amigas e um amigo do programa de inclusão social, além de quatro amigos da rua. No trabalho, destacou três colegas e uma colega com quem tem mais proximidade, dois colegas e uma colega da mesma sala um pouco mais afastado, e um chefe e uma chefe mais distantes.

O átomo mínimo da participante P5 é composto de 14 elementos, no total. São destacadas três pessoas na família, a madrinha e duas primas, que moram em uma cidade distante à da participante. Na amizade, destaca um amigo mais próximo e uma amiga que está morando distante. Na comunidade, destaca duas vizinhas. No trabalho, coloca mais próximo dela uma

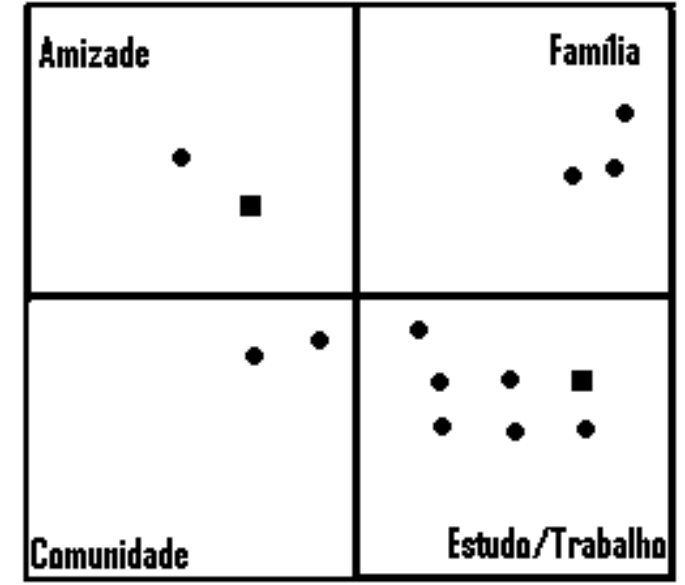

- = Mulher $\quad \boldsymbol{m}=$ Homem Figura 5. Atomo minimo do Participante 5 (P5)

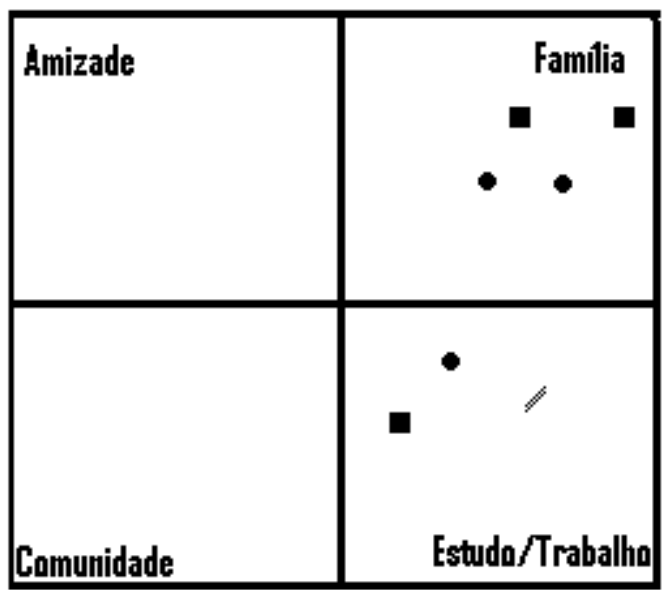

- = Mulher $\boldsymbol{\|}=$ Hormem $\|=$ Local Figura 6 Atomo mínimo do Participante 6 (P6)

colega com quem tem mais contato, e outras cinco professoras e um professor com quem trabalha.

$\mathrm{O}$ átomo mínimo do participante P6 é composto de sete elementos, sendo quatro na família e três no trabalho. Na família, colocou a mãe e a irmã como mais próximas e o pai e o irmão um pouco mais distantes. No trabalho, destacou um colega e uma colega da sala onde trabalha e um pouco mais afastado, a emergência, que o ajuda e auxilia na questão da adaptabilidade ao espaço do trabalho.

$\mathrm{O}$ átomo mínimo da participante P7 é composto por sete elementos, sendo seis na família e um na amizade. Na família destacou sua mãe, irmã e irmão como mais próximos, e sua tia, prima e sobrinho um 


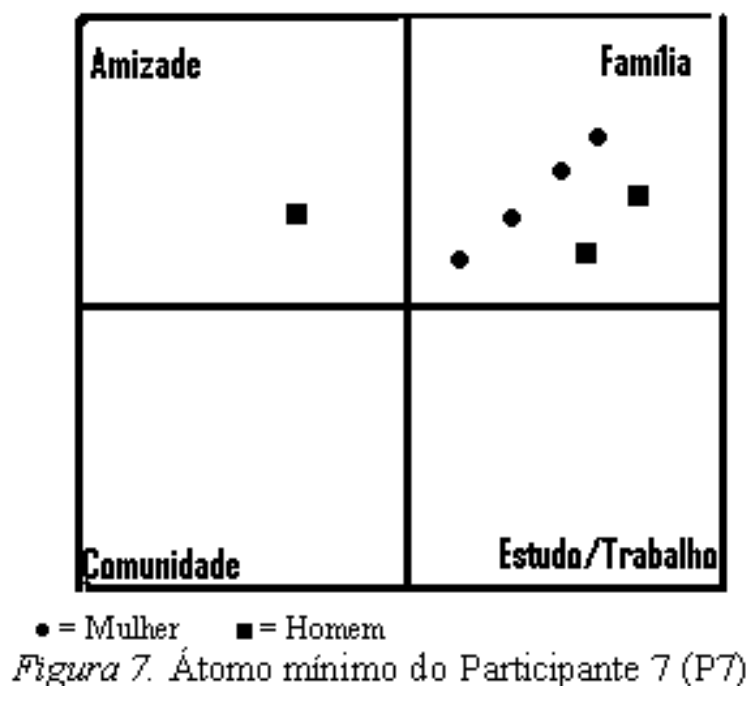

pouco mais afastados. $\mathrm{Na}$ amizade, destacou o namorado.

A participante $\mathrm{P} 1$ estava regularmente matriculada em um curso que exigia que ela estivesse sempre se movimentando e inovando as técnicas tidas como clássicas devido à sua limitação física. No desafio diário do aprendizado, contava com o apoio dos amigos, dos irmãos, às vezes até da mãe, mas os professores não se disponibilizaram a pensar novas maneiras para exercer sua profissão. Os professores representam a própria conserva da academia ao transmitir o conhecimento clássico, engessado nos livros, sem pensar em uma nova maneira, uma forma criativa, instituinte.

Foi mais a questão mesmo de estudar, e eu preciso da técnica e uma outra forma de fazer aquela técnica sem ferir o princípio. (...) Uma outra forma... a técnica que ensina é regra. Então, qual é a outra forma que eu posso fazer? (Participante P1).

Após vencer a conserva acadêmica, inovando e propondo novas técnicas, $\mathrm{P} 1$ pôde se deparar com uma nova etapa em seu curso.

As matérias [do início] têm esse cunho de introjetar na gente essa ideologia da enfermagem, o papel do enfermeiro. Então eu percebi que [hoje] a abertura é maior. É um pouco maior por não ter essa base tão rígida, física, né, nas técnicas. Aí eu tô achando que tá um pouco mais flexível, maleável nesse sentido. (Participante P1).

É interessante como P1, além de propor aos professores que saiam do seu papel conservado - de ensinar a conserva - também se propõe a usar sua espontaneidade em seu papel de aluna. Ao invés de simplesmente aceitar as técnicas propostas e absorvê-las, ela se propõe a repensar a técnica e a adaptá-la, ensinando uma nova maneira ao professor. A fala do P1 revela o aspecto amplamente discutido entre pesquisadores da área de educação especial que se refere à necessidade de formação do corpo docente para atuarem frente à diversidade (Castanho \& Freitas, 2005; Dall'acqua, 2007; Thoma, 2006; Vitaliano, 2007). Os estudiosos são unânimes em afirmar que a universidade deve extrapolar a formação acadêmica centrada no conhecimento científico, devendo se configurar em um espaço onde os valores e práticas de educação inclusiva sejam vivenciados.

Além da sociedade, as características pessoais também podem facilitar ou dificultar a inserção das pessoas com necessidades especiais nos diferentes grupos, assim como se observa na população geral. A maneira de enfrentamento, as crenças e valores individuais são alguns dos fatores individuais que determinam, em grande parte, a forma de inserção. Ao observar o átomo mínimo do Participante 4 (Figura 4), por exemplo, nota-se que ele é mais rico que os demais. Este participante faz uso da comunidade, vem de uma família grande e tem muitos amigos no trabalho. Ao mesmo tempo, ele não destaca ninguém na esfera da amizade. P4 desempenha seis diferentes papéis: filho, irmão, cunhado, amigo, vizinho e colega de trabalho.

Eu quero que a comunidade ganhe alguma coisa com isso. Eu quero que a rede ajude uma pessoa que não tem perspectiva para recolocá-la no mercado de trabalho, que ela tenha uma percepção maior do mundo, que é uma possibilidade que ele pode trazer, né? Então, provavelmente eu vou trabalhar 
na área da formação mesmo. (...) Dar aulas... projetos mais comunitários, né? Voltado para a comunidade mesmo. (Participante P4).

A utilização da comunidade, em especial de sua vizinhança, se destaca no átomo do participante e evidencia a diferença da relação que as pessoas das Regiões Administrativas do Distrito Federal estabelecem quando comparadas às pessoas do Plano Piloto. Holston (1993) discute a dicotomização centro versus periferia em Brasília-DF e aponta que as relações estabelecidas no Plano Piloto, o centro, são mais frias e distantes, enquanto nas Regiões Administrativas, a periferia de Brasília-DF, as relações são mais próximas e há um senso de comunidade. Esta crítica ao modernismo e à utopia da capital do país pôde ser percebida, já que os participantes que residem no Plano Piloto tiveram dificuldades em destacar pessoas da comunidade que fossem importantes em sua vida, enquanto o participante que reside em Região Administrativa do DF trouxe vizinhos e amigos de rua. $\mathrm{P} 4$ estabelece uma relação ecológica com sua cidade. Associa sua história de vida com a história de sua cidade: crescimento, pavimentação/acessibilidade, investimento em educação e melhoria de qualidade de vida. Observase ainda a preocupação em devolver à comunidade o investimento que recebeu. Sonha em poder dar aulas a crianças e jovens para que eles também possam ter acesso à educação, chegar à universidade e ter uma melhor inserção no mercado de trabalho.

Percebe-se que há diferentes maneiras de estar no mundo, de se adequar à sociedade e de estar inserido ou excluído de diferentes grupos. Essas diferenças individuais remetem à importância conceitual de papel e contrapapel. O papel aponta diferentes formas assumidas pelo eu, que surgem de experiências passadas e de padrões culturais (Fox, 2002; Moreno, 1975). Os papéis são desempenhados na interação com o outro, e por isso necessitam de um contrapapel, que é seu complementar. Desempenhar o papel de mãe exige o papel complementar de filho, o papel de professor exige o de aluno (Bustos, 2001). Assim, uma pessoa só assume o papel de excluída se tiver um outro que a exclui. Entretanto, a sociedade só exclui as minorias na medida em que essas desempenham tal papel. Por mais difícil que seja sair dos vínculos e quebrar a complementaridade de papéis, como de vítima e algoz, as pessoas enfrentam diariamente este desafio em busca de sua saúde. Uma pessoa com deficiência enfrenta ainda mais dificuldades em quebrar seus contrapapéis, devido às barreiras físicas que lhe são impostas. Por exemplo, uma pessoa em cadeira de rodas que deseja sair do papel de doente, mas que permanece dentro de casa, tem que enfrentar o meio-fio na porta da sua casa, e correr o risco de cair.

A utilização do átomo mínimo e os insights dele decorrentes demonstraram o potencial diagnóstico e interventivo desse instrumento. Os participantes tiveram a oportunidade de visualizar a configuração de sua rede e assim acessar a geografia de sua existência. Após a entrevista, alguns participantes relataram satisfação por terem tido a oportunidade de refletir sobre suas relações, sobre a importância das pessoas de seu dia-a-dia e das diferentes esferas de interação social. Alguns falaram que nunca tinham percebido a importância da família como uma rede de suporte, outros mencionaram a relevância da amizade e dos poucos vínculos estabelecidos. Houve ainda quem se incomodou com a ausência da comunidade em seu átomo mínimo, manifestando o desejo de passar a dispor mais desse espaço para ampliar seus relacionamentos.

A questão da comunidade é um aspecto que merece especial destaque. A pós-modernidade e o advento da internet reorganizaram a sociedade e criaram um espaço até então inexistente: o virtual. A criação de comunidades na rede de relações virtuais, de amigos de internet é um aspecto hoje ainda pouco explorado. Nicolaci-da-Costa (2005) discute os espaços contemporâneos e o impacto na vida dos indivíduos a partir do surgimento da internet e de espaços privativos móveis - os celulares. O ciberespaço é tido como um espaço autônomo em que a humanidade vive atualmente. É um local em que solidariedade, coesão social, resistência, movimentos políticos, e vida comunitária são colocados em prática de diferentes maneiras, em uma realidade imaginária, compartilhada por uma rede de computadores. Nesse espaço são criadas novas formas de vigilância, poder e controle (Nicolaci-da-Costa, 2005). 
O Orkut, por exemplo, possibilita a aglomeração de pessoas em comunidades com interesses afins, que expõem suas idéias e pensamentos na rede, possibilitando o encontro de pessoas que fazem parte dos relacionamentos reais em um espaço virtual (Conceição \& Auad, 2006). Na fala de P5, percebese a importância da internet em sua inclusão social.

Mas engraçado que agora a gente se corresponde pela internet. (...) A gente conversava muito pela internet, a gente estudava... (Participante P5).

A internet, presente na vida dos participantes da pesquisa e apontada como importante fonte de interação social por um deles, talvez possibilite outra dimensão da inserção social das pessoas com necessidades especiais. No espaço virtual, a deficiência física não é evidenciada e nem fica em destaque. Ao contrário, ela pode ser acobertada e disfarçada. $\mathrm{O}$ espaço virtual também não impõe as barreiras que essas pessoas enfrentam diariamente em suas interações sociais, o que pode fazer com que se sintam mais à vontade e menos testadas em suas limitações, como a presença de barreiras físicas e a dificuldade de locomoção. Ao facilitar as interações sociais e quebrar barreiras físicas e psicossociais, a internet pode ser benéfica às pessoas com necessidades especiais, mas a limitação das interações a esse espaço pode empobrecer a qualidade dos vínculos. As relações no espaço virtual acontecem sem o contato, sem o tato. Sem o olho no olho, sem o toque, sem um abraço. Contato este que é fundamental na constituição do eu.

O relatório da UNESCO (Moreno Valdés, 2005) destaca que nas décadas de 1980 e 1990 ocorreu ampliação do número de acessos à educação superior. Entretanto, a entrada foi restrita aos candidatos que não exigiam mudanças acentuadas nos processos seletivos devido à falta de adaptações. Barreiras arquitetônicas e atitudinais dificultavam a permanência com sucesso desses alunos na universidade. Entretanto, a pequena quantidade de relações destacada nos átomos mínimos, evidencia que algumas barreiras são ainda hoje enfrentadas pelos alunos com necessidades especiais.
Ao evidenciar a exclusão em diferentes esferas da vida do deficiente, é preciso refletir sobre as barreiras na ampliação de seus átomos mínimos. Os alunos que chegaram à universidade já ultrapassaram muitas barreiras, como a taxa de escolaridade em pessoas com deficiência: 11 milhões de pessoas com deficiência, com 15 anos ou mais, não têm nenhuma ou têm baixíssima escolaridade (Fundo das Nações Unidas para a Infância [Unicef], 2003). A barreira a enfrentar é outra: a da real inclusão. O preconceito talvez seja a barreira mais evidente e a necessidade de fortalecer a auto-imagem pode ser percebida na leitura clínica das falas dos participantes. Mas, afinal, quem é deficiente? A pessoa com necessidades especiais ou a sociedade que não permite que ela seja verdadeiramente incluída?

$\mathrm{Na}$ esfera familiar, percebe-se que os deficientes que sofreram lesão medular relatam melhora no relacionamento familiar após o acidente. Os deficientes que têm doenças crônicas relatam dificuldade com relação à superproteção dos pais e necessidade de negociar sua liberdade e independência. A Participante 1 (Figura 1), por exemplo, tinha uma doença crônica e estava enfrentando dificuldades com a mãe na busca por sua liberdade e independência, como pode ser percebido na fala abaixo.

Essa questão da proteção tava atrapalhando muito essa coisa da vida social. Quando os outros podem sair, eu tô estudando e quando eu quero sair, tem um ou dois que podem ou que querem sair. Então eu tive que negociar, porque, por exemplo, pra minha mãe, um ou dois, dependendo de quem são esses um ou dois é como se eu tivesse saindo sozinha e se eu sair sozinha, é perigoso. Tive que negociar muito. (...) Aí eu 'mãe, eu quero sair com a minha amiga, e não com uma cuidadora, uma babá, eu quero sair com uma amiga. Eu cuido de mim. Eu cuido dela, qualquer coisa a gente se ajuda. Essa é a questão da amizade: um ajuda o outro. E qualquer coisa, eu tô de celular, ela também, você tá em casa... (Participante P1). 
O Participante P6, por outro lado, relatou que as relações com a mãe e a irmã são harmoniosas, e que melhoraram muito após o acidente:

Com minha família meu relacionamento tá muito bom. Muito melhor do que antes do acidente. (...) O que que aconteceu? Eu não, eu não me dava bem com minha mãe. E hoje eu me dou muito bem com minha mãe. (...) Foi um grande ganho. A minha irmã começou a cuidar de mim quando minha mãe começou a trabalhar. A gente mal, quase não se falava. (Participante P6).

A universidade, para a maior parte dos entrevistados, foi percebida como um ambiente em que se sentiram mais acolhidos e onde desenvolveram laços de amizade e afetividade. O Participante P2 destaca a universidade como um local de desenvolvimento do papel de amigo, em especial com um colega com quem conversa bastante e se relaciona muito bem.

Ele é meu melhor amigo aqui na universidade. (...) Aqui na universidade, eu acho que eu convivo legal com todo mundo. E é do jeito que deve ser, sei lá, mais ou menos. Já foi melhor, mas, aqui todo mundo fala comigo, você viu, né? Todo mundo fala comigo. Sempre... quis ser a pessoa legal e diferente. (...) Aqui [na universidade] é beleza. Aqui é o melhor lugar! (Participante P2).

Nenhum dos entrevistados relatou dificuldades de inserção no mercado de trabalho, o que pode ser justificado pela reserva de vagas nos concursos públicos, principalmente quando todos os participantes que trabalham são funcionários públicos. O Participante 6 (P6) destaca que foi fácil sua entrada no mercado de trabalho, assim como P4.

Então, está super tranqüilo [o mercado de trabalho]. (Participante P6).

Eu queria era emoldurar minha primeira nota. Não queria gastá-la. Porque claro, eu não tinha perspectiva de trabalho, pensei que eu não ia trabalhar. Até que eu comecei a estudar, não foi na idade normal. (...) E aí na escola teve um desses cursos profissionalizantes, era de informática, trabalhava com o Windows 95. E aí eu fiz o curso (...) E eu fui um dos que ficaram, e aí tinha um projeto lá na instituição. (...) E aí recebi, uma nota de 50 reais. Fiquei com ela um tempo, porque eu tava em estado de êxtase: "Nossa, suor do meu trabalho!" (...) E daí em diante dentro da administração eu fui requisitado pra trabalhar de novo (...), já com um pagamento bom. (...) E aí depois que eu saí daí eu fiquei como autônomo mesmo, assim trabalhos de instalação de redes, softwares, manutenção de micros, tinha uns contatos no comércio local, e aí ia tirando um dinheirinho fazendo isso. Até que eu fiz. esse concurso, foi o primeiro concurso que eu tinha feito, e passei. (Participante P4).

Sugere-se que novas pesquisas investiguem a inserção social na vida universitária de pessoas que não tenham necessidades especiais. Com esses dados em mãos, torna-se possível comparar a inserção das pessoas com e sem necessidades especiais na universidade e identificar as semelhanças e diferenças. Sugere-se ainda investigar o grupo de pessoas com necessidades especiais que não contam com o apoio do programa de inclusão social. Tendo acesso a esse grupo, será possível investigar como é a percepção deles de sua inserção na vida universitária, e identificar as possíveis causas para essa não procura - falta de conhecimento, preconceito, dificuldade de se perceber como deficiente.

A diversidade é muito enriquecedora para as empresas, não apenas por reforçar sua imagem na sociedade, mas também por gerar melhoras no desempenho organizacional. A qualidade dos serviços prestados, a produtividade e eficiência, assim como a redução na síndrome de burnout são os impactos gerados nas empresas que adotam políticas de inserção plural, que gera aumento de lucro (Cox, 1994). 
É preciso pensar em maneiras de enriquecer os átomos em especial no ambiente de estudo/trabalho e na comunidade, que se destacaram como os mais empobrecidos, tendo em vista que os princípios da exclusão encontram-se imbuídos nas relações. A inclusão torna-se possível na medida em que seja ensinada a tolerância e o respeito à diversidade, uma vez que os princípios da exclusão encontram-se imbuídos nas relações.

\section{Referências}

Ausloos, G. (1998). Las capacidades de la família: Tiempo, caos y proceso. Barcelona: Herder.

Bustos, D. (1979). O teste sociométrico: Fundamentos, técnica e aplicações. São Paulo: Brasiliense.

Bustos, D. (2001). Perigo... amor à vista!: Drama e psicodrama de casais (N. de P. Lima, Trad.). São Paulo: Aleph.

Castanho, D. M., \& Freitas, S. N. (2005). Inclusão e prática docente no ensino superior [Versão Eletrônica]. Revista Educação Especial, 27. Recuperado em 10 junho 2008, de http:// coralx.ufsm.br/revce/ceesp/2006/01/a6.htm

Conceição, M. I. G. (2000). Biofeedback eletromiográfico na reabilitação de portadores de lesão medular. Tese de Doutorado nãopublicada, Universidade de Brasília, Brasília.

Conceição, M. I. G., \& Auad, J. C. (2006, agosto). Orkut psicodramático [Resumo]. In Federação Brasileira de Psicodrama (Org.), Congresso Brasileiro de Psicodrama,15. São Paulo: FEBRAP.

Correr, R. (2003). Deficiência e inclusão social. Bauru, SP: Edusc.

Costa, M. I. M., \& Vanin, M. R. C. L. (2005). O reencontro com a identidade de gênero: Contribuições da visão sistêmica novoparadigmática e do psicodrama infantil. Estudos de Psicologia, 22, 175-185.
Cox, T. (1994). Cultural diversity in organizations: Theory, research and practice. San Francisco: Berrett-Koehler.

Dall' acqua, M. J. C. (2007). Atuação de professores do ensino itinerante face à inclusão de crianças com baixa visão na educação infantil. Paidéia (Ribeirão Preto), 17, 115-122.

Demo, P. (2001). Pesquisa e informação qualitativa: Aportes metodológicos. Campinas, SP: Papirus.

Diaz, A. L. A. (1995). Historia de las deficiencias. Madrid: Escuela Libre.

Eide, A., \& Roysamb, E. (2002). The relationship between level of disability, psychological problems, social activity, and social networks. Rehabilitation Psychology, 47, 165-183.

Fox, J. (2002). O essencial de Moreno: Textos sobre psicodrama, terapia de grupo e espontaneidade (M. Aguiar, Trad.). São Paulo: Ágora.

Fundo das Nações Unidas para a Infância. (2003). Relatório da situação da infância $e$ adolescência brasileiras, diversidade $e$ equidade. Recuperado em 10 janeiro 2007, de http://www.unicef.org/brazil/

González-Rey, F. G. (2002). Pesquisa qualitativa em psicologia: Caminhos e desafios (M. A. F. Silva, Trad.). São Paulo: Pioneira Thomson Learning.

Grandesso, M. A. (2000). Quem é a dona da história? In H. M. Cruz (Org.), Papai, mamãe, você... E eu?: Conversações terapêuticas em famílias com crianças (pp.101-122). São Paulo: Casa do Psicólogo.

Holston, J. (1993). A cidade modernista: Uma crítica de Brasília e sua utopia (M. Coelho, Trad). São Paulo: Companhia das Letras.

Knobel, A. M. (2004). Moreno em ato: A construção do psicodrama a partir das práticas. São Paulo: Ágora. 
Lopes, G. B., Kato, L. S., \& Corrêa, P. R. C. (2002). Os pais das crianças com deficiência: Reflexões acerca da orientação em reabilitação motora. Psicologia: Teoria e Prática, 4, 67-72.

Marineau, R. F. (1992). Jacob Levy Moreno: O pai do psicodrama, da sociometria e da psicoterapia de grupo (J. S. e M., Werneck, Trad.). São Paulo: Ágora.

Monte, F. R. F., \& Santos, I. B. dos (2004). Saberes e práticas da inclusão: Dificuldades de comunicação e sinalização: Deficiência física. Brasília: MEC.

Moreno, J. L. (1975). Psicodrama (A. Cabral, Trad.). São Paulo: Cultrix.

Moreno, J. L. (1994). Quem sobreviverá?: Fundamentos da sociometria, psicoterapia de grupo e sociodrama (Vol. 2, D. L. Rodrigues \& M. A. Kafuri, Trads.). Goiânia: Dimensão.

Moreno, J. L. (1999). Psicoterapia de grupo e psicodrama (J. C. V. Gomes, Trad.). São Paulo: Mestre Jou.

Moreno Valdés, M. T. (Coord.). (2005). A integração das pessoas com deficiência na educação superior no Brasil. Recuperado em 11 agosto 2008, de http://sid.usal.es/idocs/F8/FDO12676/ integracion_educacion_superior_brasil.pdf

Naffah Neto, A. (1979). Psicodrama: Descolonizando o imaginário. São Paulo: Brasiliense.

Naffah Neto, A. (1989). Paixões e questões de um terapeuta. São Paulo: Ágora.

Nery, M. P., Costa, L. F., \& Conceição, M. I. G. (2006). O sociodrama como método de pesquisa qualitativa. Paidéia (Ribeirão Preto), 16, 305313.

Nery, M. P (2003). Vínculo e afetividade: Caminhos das relações humanas. São Paulo: Ágora.

Nicolaci-da-Costa, A. M. (2005). O Cotidiano nos múltiplos espaços contemporâneos. Psicologia: Teoria e Pesquisa, 21, 365-373.
Organização Mundial de Saúde. (1997). International classification of impairments, activities, and participation (ICIDH-2). Geneva, Switzerland: Author. Recuperado em 20 março 2006, de http://www.who.int/en/

Seixas, M. R. A. (1992). Sociodrama familiar sistêmico. São Paulo: Aleph.

Sherman, J., Devinney, D., \& Sperling, K. (2004). Social support and adjustment after spinal cord injury: Influence of past peer-mentoring experiences and current live-in partner. American Psychological Association, 49, 140-149.

Sluzki, C. E. (1997). A rede social na prática sistêmica: Alternativas terapêuticas. São Paulo: Casa do Psicólogo.

Thoma, A. S. (2006). A inclusão no ensino superior: "Ninguém foi preparado para trabalhar com esses alunos (...) isso exige certamente uma política especial...". Recuperado em 7 junho 2008, de http:// www.anped.org.br

Tuleski, S. C., Taguchi, D. M., Alves, L., Oliveira, P. P., \& Marques, S. P. (2003). Educação especial: A família como foco. In M. C. Marquezine, M. A. Almeida, S. Omote (Orgs.), O papel da família junto ao portador de necessidades especiais (pp. 97-109). Londrina: EdUEL.

Vasconcellos, M. J. E. (2004). Implicações do pensamento sistêmico novo-paradigmático: A questão da dicotomia "terapia familiar sistêmica"/ "terapia familiar narrativista". Nova Perspectiva Sistêmica, 12(24), 7-13.

Verbrugge, L. M., \& Jette, A. M. (1994). The disablement process. Social Science \& Medicine, 38, 1-14.

Vitaliano, C. R. (2007). Análise da necessidade de preparação pedagógica de professores de cursos de licenciatura para a inclusão de alunos com necessidades educacionais especiais. Revista Brasileira de Educação Especial, 13, 399-414. 
154 Paidéia, 2008, 18(39), 139-154

Artigo recebido em 15/04/2007.

Aceito para publicação em 19/04/2008.

Apoio financeiro: CAPES. Trabalho derivado da dissertação de Mestrado defendida no Programa de Pós-graduação em Psicologia Clínica e Cultura da Universidade de Brasília/UnB, sob supervisão da Profa. Dra. Maria Inês Gandolfo Conceição.

Endereço para correspondência:

Juliana Cal Auad. SHIGS 706 Bl C, cs. 03. CEP 70350-753. Brasília-DF, Brasil. E-mail: julianaauad@yahoo.com.br

Juliana Cal Auad é mestre em Psicologia Clínica e Cultura pela Universidade de Brasília.

Maria Inês Gandolfo Conceição é Professora Adjunto do Instituto de Psicologia da Universidade de Brasília. 